\title{
Adaptive mechanism of the bimodal emergence dates in the intertidal midge Pontomyia oceana
}

\author{
Keryea Soong*, Yijye Leu
}

Institute of Marine Biology, National Sun Yat-sen University, 70 Lien-Hai Road, Kaohsiung, 804 Taiwan, ROC

\begin{abstract}
The intertidal midge Pontomyia oceana (Diptera: Chironomidae) emerges semilunarly, about 15 d apart, in southern Taiwan. Fertilized eggs laid on the same night develop into adults that show emergence peaks about 30 and 45 d later. We tested 2 hypotheses: (1) 'two adaptive peaks'; adult midges emerging in each peak are adapted to certain environments and (2) 'bet-hedging'; late emergence is not adaptive in itself but acts as an insurance against risk of total loss of offspring from a single emergence. In our experiment, the percentage of the cohort that emerged in the first peak had a strong environmental component, but individuals emerging in 2 peaks did not differ in plastic traits such as fecundity, male head length and male thorax length. The 'two adaptive peaks' hypothesis is not supported. Offspring of most individual mothers showed bimodal emergence under homogeneous laboratory conditions. Highly unpredictable wind speed may cause variable success rates of mating on the water surface. By allocating some offspring to a second available window, the midges ensure higher fitness in the long-term in an unpredictable environment. The offspring of some females, nevertheless, only emerged in the first peak. We propose an intermittent bet-hedging strategy in which midges need not produce offspring in both peaks in every generation. As the benefits of bet hedging are only realized over multiple generations, offspring can be distributed in multiple peaks even if offspring do not emerge in 2 peaks in every generation.
\end{abstract}

KEY WORDS: Semilunar rhythm · Marine insect · Dimorphism · Bet-hedging

Resale or republication not permitted without written consent of the publisher

\section{INTRODUCTION}

Intertidal zones are highly variable environments (Lewis 1964). The ebb and flow of tides, combined with the cycle of sunrise and sunset and seasonal changes in photoperiod, cause fluctuations in salinity, temperature, and exposure, as well as in predators and competitors for the organisms living in this habitat. Special adaptations are necessary for exploitation of this habitat (see, e.g. Neumann 1976, Kubler \& Davison 1993, Zebe \& Schiedek 1996, Schmidt \& Rand 1999). As the photoperiod and tides are predictable, organisms can follow these environmental cycles with entrained endogenous rhythms (Neumann \& Heimbach 1985, Neumann 1986, Palmer 1996). Many examples of organisms with tidal, daily, semilunar, and lunar rhythms have been reported in intertidal zones (Foster \& Moreton 1981, Ruyck et al.
1991, Omori 1995, Saigusa \& Akiyama 1995, Sunobe et al. 1995).

Predictable environmental cycles often include unpredictable components (Solbreck 1991). For example, the sun rises at a predictable time every day, but cloud cover determines when the sunlight can be detected by organisms (Nadeau et al. 1999). Besides predictable cycles, there are also unpredictable factors and they may have major effects on the reproductive success of organisms (see, e.g. Bologna 1998, Forcada et al. 1999). For example, although hurricanes occur predominantly in summer, occurrence of a hurricane on any particular date is highly uncertain (see Lu \& Chen 1998). Similarly, the abundances of prey and predators can vary greatly and present great uncertainty to organisms (see Morgan \& Christy 1994). Short-lived organisms are more likely than others to be affected by environmental variability, because their 
life cycles are shorter than the possible fluctuation periods. For example, individuals living 1 mo apart may experience very different environments and be subject to very different selection pressures.

The marine midge Pontomyia oceana lives in the semiclosed tidal pools of Wanliton, southern Taiwan $\left(22^{\circ} 00^{\prime} \mathrm{N}, 120^{\circ} 42^{\prime} \mathrm{E}\right)$. Adults emerge in large and variable numbers on 3 to 4 consecutive nights, bracketing new moons and full moons (Chen 1993, Soong et al. 1999). After emerging, adults live for about $2 \mathrm{~h}$, during which males find immobile females and mate. The surface-skating males then drag the degenerate females to the exposed substratum, where the latter lay a sticky egg string (Chen 1993, Cao 1997, Soong et al. 1999). Preliminary observations revealed that a batch of fertilized eggs, collected on the same night in the field, later emerged as adults in 2 peaks, approximately 30 and 45 d later in the laboratory (Lee 1999).

Two hypotheses can be invoked to explain this bimodality in emergence. The first, 'two adaptive peaks', is that 2 types of offspring, namely early and late emergers, emerging after about 30 and $45 \mathrm{~d}$, respectively are adapted to different environments. Early emergers, because of their more rapid development, may have lower fecundities or lower competitive abilities than late emergers. The 2 groups may also differ in dispersal ability or other characteristics other than emergence date. Assuming this hypothesis, the difference in emergence dates could be attributable to genetic and/or environmental differences. Many organisms show similar dimorphisms, although not necessarily in the timing of life-history events. For example, the semelparous coho salmon has 2 mating strategies: large, competitive, old males and small, sneaky, young males coexist in the population (Gross 1991). Several polychaetes are known to produce both planktotrophic and lecithotrophic larvae (Blake \& Kudenov 1981, Levin 1984, Qian \& Chia 1992). Production of different types of larvae, poecilogony, is also reported in an opisthobranch mollusc (Krug \& Zimmer 2000). Notably, a rain pool midge Chironomus imicola, in the same family as the marine midge of this study, is known to produce 2 morphs of larvae with different emergence times (McLachlan 1989, McLachlan \& Ladle 2001). The mechanisms causing these dimorphisms are not necessarily clear, but each morph is presumed to have an adaptive value.

The alternative hypothesis, 'bet-hedging,' is that otherwise similar offspring are allocated to 2 emergence peaks so that short-term adverse conditions are less likely to destroy the parents' entire reproductive output. This strategy confers greater long-term fitness but imposes the cost of producing some offspring with late emergence times. As the emergence time within each day is highly synchronized (Chen 1993, Soong et al. 1999), bet-hedging may be important to Pontomyia oceana. Many organisms employ bet-hedging (Philippi \& Seger 1989, Hopper 1999). For example, the seeds of desert plants do not all germinate in the year after they are produced. Some remain dormant until a future season (Philippi 1993, Pake \& Venable 1996, Narita 1998). A similar strategy is used by desert bees (Danforth 1999), as well as many other insects, which produce diapausing propagules (see, e.g. Bradford \& Roff 1997, Simovich \& Hathaway 1997) or have bimodal or polymodal emergence after termination of diapause (Waldbauer 1978, Collier et al. 1989).

The intertidal habitat of Pontomyia oceana has a potential for great risk at and immediately after midge emergence, and unfavorable conditions above water cannot be detected or predicted by the midge larvae before emergence. Individual midges can reduce the probability of losing all offspring to a single short-term adverse situation by delaying emergence of a certain percentage of their offspring. By spreading the risk, they may suffer lower short-term fitness due to the delayed maturity of some of the offspring, but this strategy produces a long-term benefit because the variation in fitness among generations is lowered, and the geometric mean fitness may be higher than that of midges whose offspring all emerge together. The early and late emergers need not have morphological or fitness differences, because selection works on the parents' reproductive success under this hypothesis.

These 2 hypotheses involve different assumptions and make different predictions (summarized in Table 1). We sought to be able to differentiate between them by determining whether early and late emergers differ in other characteristics and whether individual females differ in the proportions of offspring emerging early and late.

\section{MATERIALS AND METHODS}

Study species. Male Pontomyia oceana, together with attached mating females, were attracted with lights and collected on evenings of mass emergence at Wanliton $\left(22^{\circ} 00^{\prime} \mathrm{N}, 120^{\circ} 42^{\prime} \mathrm{E}\right)$, southern Taiwan. Fertilized eggs, in sticky strings, were kept immersed in containers of seawater. Larvae hatched in 3 to $4 \mathrm{~d}$. The larvae were cultured under standard conditions of 1000 to $1500 \mathrm{~lx}$ surface illumination, 12:12 h light:dark (LD) photoperiod, and $25 \pm 1{ }^{\circ} \mathrm{C}$ and fed $0.5 \mathrm{~g}$ alga powder $3 \mathrm{~d}^{-1}$, without water level changes.

Environmental factors. We varied several environmental factors to explore the plasticity of emergence peaks and to identify plastic traits of midges that could be used for comparison of midges emerging early and late. The effects of 2 environmental factors, amount of food and photoperiod, on emergence date were studied 
Table 1. Predictions of 2 hypotheses - 'two adaptive peaks' and 'bet-hedging' that might explain the bimodal emergence of adult Pontomyia oceana. The results support the bet-hedging hypothesis

\begin{tabular}{|c|c|c|c|}
\hline Trait & $\begin{array}{l}\text { Two adaptive } \\
\text { peaks }\end{array}$ & Bet-hedging & Results \\
\hline $\begin{array}{l}\text { Emergence pattern } \\
\text { of offspring from a } \\
\text { single mother }\end{array}$ & Uni- or bimodal & Bimodal & $\begin{array}{l}\text { Uni- or } \\
\text { bimodal }^{\mathrm{a}}\end{array}$ \\
\hline $\begin{array}{l}\text { Fecundity of late } \\
\text { emergers }\end{array}$ & $\begin{array}{l}\text { Greater than that } \\
\text { of early emergers }\end{array}$ & $\begin{array}{l}\text { Equal to that of } \\
\text { early emergers }\end{array}$ & $\begin{array}{l}\text { Equal to that of } \\
\text { early emergers }\end{array}$ \\
\hline $\begin{array}{l}\text { Male traits of early } \\
\text { and late emergers }\end{array}$ & Differ & Do not differ & Do not differ \\
\hline $\begin{array}{l}\text { Susceptibility of } \\
\text { emergence pattern } \\
\text { to modification by } \\
\text { environmental factors }\end{array}$ & $\begin{array}{l}\text { Depends on } \\
\text { whether the } \\
\text { pattern is } \\
\text { genetically } \\
\text { determined }\end{array}$ & $\begin{array}{l}\text { Percentage of } \\
\text { early emergers } \\
\text { may vary }\end{array}$ & $\begin{array}{c}\text { Percentage of } \\
\text { early emergers } \\
\text { vary }\end{array}$ \\
\hline \multicolumn{2}{|l|}{$\begin{array}{l}\text { Characteristics of early } \\
\text { and late emergers other } \\
\text { than emergence time }\end{array}$} & Do not differ & Do not differ \\
\hline \multicolumn{2}{|l|}{ a'See details in 'Discussion' } & & \\
\hline
\end{tabular}

hourly wind speeds between 19:00 and 23:00 h (i.e. 4 data points per day) were used as an index of the wind speeds the emergent Pontomyia oceana was likely to experience on the water surface. The wind speed correlation between consecutive days as well as that for days $15 \mathrm{~d}$ apart was calculated for the interval between 1999 and 2000.

\section{RESULTS}

\section{Environmental factors}

Two emergence peaks occurred in each of the 3 feeding groups (Fig. 1), and groups differed in percentage of early emergers ( $p<0.05$, Kruskal-Wallis test); the percentage of early emergers was higher when food was more abundant (Table 2). separately. In the feeding experiment, 3 feeding regimes were used: $0.5,0.1$, and $0.02 \mathrm{~g}$ of alga powder per $2 \mathrm{l}$ bottle every $3 \mathrm{~d}$. In the photoperiod experiment, 3 light regimes were used: L:D 10:14, L:D 12:12, and L:D 14:10 h. Three replicate bottles were used for each treatment in these experiments. The number of midges that emerged in each container each day was recorded for $60 \mathrm{~d}$; fertilization day was Day 0. The 38th day, halfway between the 30th and 45 th days, was used as the boundary between the 2 emergence peaks. The percentage of offspring that emerged in the earlier peak was determined for each bottle and each treatment.

Morphological characteristics of early- and lateemerging adult males and females were also compared. Fecundities were recorded for those females with egg strings that did not stick to other females; the diameters of 6 eggs per individual were measured. The head and thorax lengths of the males were determined under a microscope with a calibrated ocular micrometer.

Single-mother culture. To determine the allocation of offspring of individual mothers to early and late emergence, we collected egg strings of individual mothers, raised them in separate bottles, and determined the percentage emerging in the early peak. Siblings of each family were mated to one another, and isolated females produced the next generation. The same procedure was followed for a total of 5 generations.

Local wind analysis. We chose wind speed as an environmental factor likely to affect adult midge behavior on the water surface. Hourly wind speed data for Hengchun, a few kilometers from the study site, was obtained from the Central Weather Bureau of Taiwan. The
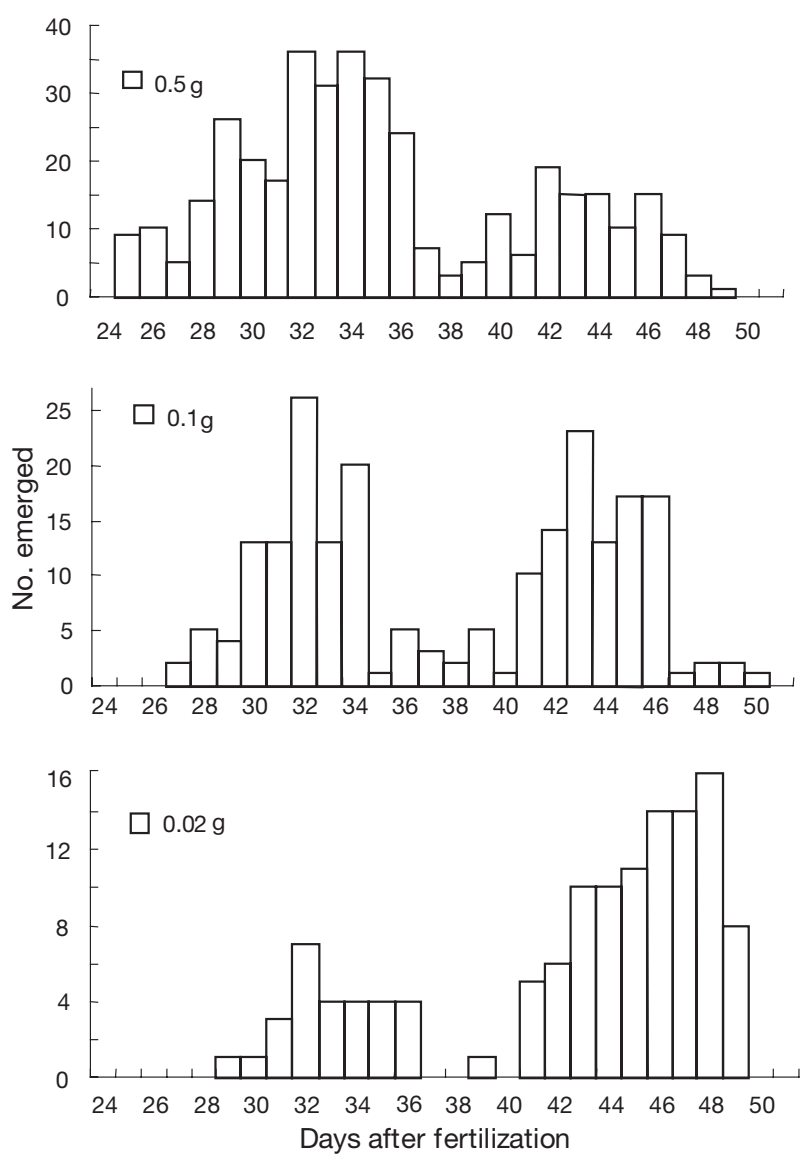

Fig. 1. Pontomyia oceana. Daily emergence frequencies in the feeding experiment. Each bar represents the mean of 3 bottles of midges. Time to emergence was bimodal in all 3 treatments, but the percentage of early emergers was higher when food was more abundant (Kruskal-Wallis test, $\mathrm{p}<0.05$ ) 
Early and late emergers in this experiment did not differ significantly in fecundity, egg length, male head length, or male thorax length (Table 3).

Greater food abundance did produce higher fecundities, male head lengths, and male thorax lengths, however $(\mathrm{p}<0.01$ in all comparisons, Kruskal-Wallis test, Table 3 ). Feeding regime did not significantly affect egg length.

Two emergence peaks also occurred under each of the 3 photoperiods (Fig. 2), but photoperiod treatments did not differ significantly in percentage of early emergers ( $p<0.05$, Kruskal-Wallis test, Table 2). Neither early and late emergers nor midges raised under

Table 2. Pontomyia oceana. Numbers of males and females emerging in the early and late peaks in the feeding and photoperiod experiments (means of 3 bottles). The percentage of early emergers (mean $\pm \mathrm{SE}$ ) was significantly higher when food was more abundant (Kruskal-Wallis test, $\mathrm{p}<0.05$ ), but food abundance did not significantly affect sex ratio (chi-square test), and photoperiod did not significantly affect either variable when the effects of multiple testing were accounted for

\begin{tabular}{|lccc|}
\hline Treatment & $\begin{array}{c}\text { Early emergers } \\
\text { males/females }\end{array}$ & $\begin{array}{c}\text { Late emergers } \\
\text { males/females }\end{array}$ & $\begin{array}{c}\text { Early } \\
\text { emergers (\%) }\end{array}$ \\
\hline Feeding (g alga powder bottle ${ }^{-1} \mathrm{~d}^{-1}$ ) & & \\
0.5 & $114 / 123$ & $58 / 52$ & $68 \pm 6$ \\
0.1 & $54 / 51$ & $51 / 55$ & $52 \pm 9$ \\
0.02 & $17 / 11$ & $54 / 41$ & $18 \pm 10$ \\
Photoperiod (L:D h) & & & $72 \pm 20$ \\
$10: 14$ & $59 / 124$ & $39 / 72$ & $85 \pm 3$ \\
$12: 12$ & $115 / 221$ & $28 / 37$ & $63 \pm 22$ \\
$14: 10$ & $72 / 199$ & $50 / 82$ & \\
& & & \\
\hline
\end{tabular}

Table 3. Pontomyia oceana. Fecundities, egg sizes, and male head and thorax lengths of early- and late-emerging individuals in the feeding experiment (treatment as in Table 2). Egg length (nested ANOVA) and fecundity and male head and thorax lengths (all Mann-Whitney $U$-test) were not significantly affected by emergence time. Egg length (nested ANOVA) was not significantly affected by feeding regime, but feeding regime did significantly affect fecundity and male head and thorax lengths (all Kruskal-Wallis test, $\mathrm{p}<0.01$ )

\begin{tabular}{|c|c|c|}
\hline Feeding regime & Early emergers & Late emergers \\
\hline \multicolumn{3}{|c|}{ Egg length $(\mathrm{mm})$ mean $\pm \mathrm{SE}$ (no. of individuals, no. of eggs) } \\
\hline $0.5 \mathrm{~g}$ & $0.144 \pm 0.007(18,108)$ & $0.146 \pm 0.011(21,126)$ \\
\hline $0.1 \mathrm{~g}$ & $0.141 \pm 0.007(7,42)$ & $0.145 \pm 0.006(14,84)$ \\
\hline $0.02 \mathrm{~g}$ & $0.148 \pm 0.005(1,6)$ & $0.146 \pm 0.008(6,36)$ \\
\hline \multicolumn{3}{|c|}{ Fecundity mean \pm SE $(\mathrm{n})$} \\
\hline $0.5 \mathrm{~g}$ & $133 \pm 26(18)$ & $129 \pm 39(16)$ \\
\hline $0.1 \mathrm{~g}$ & $86 \pm 38(7)$ & $72 \pm 36(13)$ \\
\hline $0.02 \mathrm{~g}$ & $17 \quad(1)$ & $49 \pm 21(5)$ \\
\hline \multicolumn{3}{|c|}{ Male head length $(\mathrm{mm})$ mean \pm SE $(\mathrm{n})$} \\
\hline $0.5 \mathrm{~g}$ & $0.221 \pm 0.028$ & $0.228 \pm 0.018$ \\
\hline $0.1 \mathrm{~g}$ & $0.203 \pm 0.025(14)$ & $0.212 \pm 0.027(30)$ \\
\hline $0.02 \mathrm{~g}$ & $0.182 \pm 0.010(13)$ & $0.180 \pm 0.021(40)$ \\
\hline \multicolumn{3}{|c|}{ Male thorax length $(\mathrm{mm})$ mean $\pm \mathrm{SE}(\mathrm{n})$} \\
\hline $0.5 \mathrm{~g}$ & $0.539 \pm 0.049$ & $0.529 \pm 0.040$ \\
\hline $0.1 \mathrm{~g}$ & $0.475 \pm 0.063(14)$ & $0.482 \pm 0.056(30)$ \\
\hline $0.02 \mathrm{~g}$ & $0.40 \pm 0.042(13)$ & $0.384 \pm 0.046(40)$ \\
\hline
\end{tabular}

\section{Single-mother cultures}

Fertilized eggs from 5 generations and 145 females successfully completed their life cycles in the laboratory. All generations except the first, the eggs for which were from wild mothers, were the result of sibling mating among early emergers. The percentage of late emergers was usually low, and cases in which males and females emerged in the same bottle on the same evening were increasingly rare. Overall, 2487 offspring emerged in the first peak, and 670 emerged in the second. Individuals varied widely in percentage of early emergers among their offspring (Fig. 3). Of the 22 lines beginning with individual females in the first generation, 6 lasted the whole 5 generations. Generations differed in the number of successful females and also differed significantly in the percentages of early emergers among the offspring of individual females $(\mathrm{p}<0.01$, Kruskal-Wallis test, Fig. 4); the second generation had the highest ( $93 \%$, all individuals pooled) and the fifth generation the lowest $(27 \%)$. Percentage of early emergers decreased at an average of $10 \%$ per generation (Fig. 4), but family lines did not differ significantly ( $p=0.63$, Kruskal-Wallis test); i.e. no family line showed a consistently high or low percentage of early emergers.

Of all the 145 breeding females in this experiment, $33(23 \%)$ produced no late-emerging offspring at all. We used binomial distribution to test for the possibility that this result could be explained by a sampling effect. Using the overall percentages of early emergence of each generation (and taking into account the effect of multiple tests (Lessios 1992), we found that chance alone could account for as many as 29 such cases but not for 33 .

\section{Local wind analysis}

The average daily wind speed at the study area ranged from 2 to $140 \mathrm{~cm}$ $\mathrm{s}^{-1}$ in 1999-2000. No wind-speed pat- 

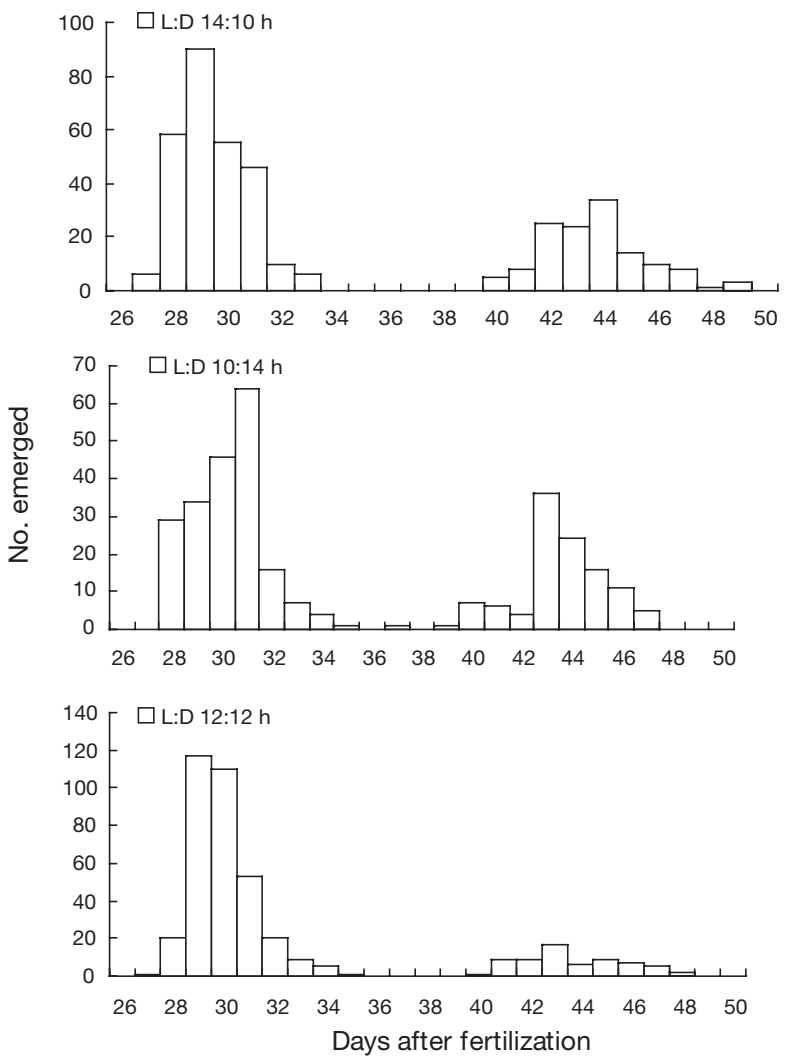

Fig. 2. Pontomyia oceana. Daily emergence frequencies in the photoperiod experiment. Each bar represents the mean of 3 bottles of midges under 1 of 3 photoperiods. Time to emergence was bimodal in all 3 treatments, and photoperiod did not significantly affect percentage of early emergers

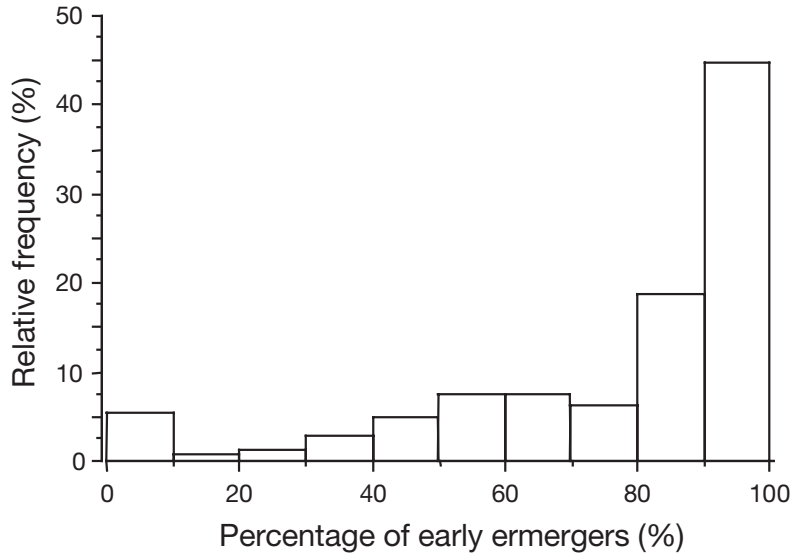

Fig. 3. Pontomyia oceana. Percentages of early emergers among offspring of individuals raised in the laboratory. Total $\mathrm{n}=145$. Many individuals (33) produced $100 \%$ early emergers

tern was obvious within a month, and the highest average wind speed seemed to occur between November and April (Fig. 5). The correlation coefficient for wind speeds between consecutive days was 0.403 ( $\mathrm{n}=731, \mathrm{p}<0.01$ ), significantly higher than that between days $15 \mathrm{~d}$ apart $(0.104, \mathrm{n}=717, \mathrm{p}<$ 0.01). The $99 \%$ confidence intervals of the 2 coefficients did not overlap.
Table 4. Pontomyia oceana. Fecundities, egg sizes, and male head and thorax lengths of early- and late-emerging individuals in the photoperiod experiment (treatment as in Table 2). No variable measured was significantly affected by photoperiod or by emergence time (egg length, nested ANOVA; fecundity and male head and thorax lengths, all Mann-Whitney $U$-test and Kruskal-Wallis test)

\begin{tabular}{|c|c|c|}
\hline Photoperiod & Early emergers & Late emergers \\
\hline \multicolumn{3}{|c|}{ Egg length $(\mathrm{mm})$ mean $\pm \mathrm{SE}$ (number of individuals, number of eggs) } \\
\hline L:D 10:14 & $0.141 \pm 0.011(7,42)$ & $0.145 \pm 0.010(4,24)$ \\
\hline L:D 12:12 & $0.134 \pm 0.009(14,84)$ & $0.144 \pm 0.010(21,126)$ \\
\hline L:D 14:10 & $0.141 \pm 0.010(14,84)$ & $0.137 \pm 0.009(21,126)$ \\
\hline \multicolumn{3}{|c|}{ Fecundity mean \pm SE $(n)$} \\
\hline L:D 10:14 & $111 \pm 24(7)$ & $99 \pm 21(3)$ \\
\hline L:D 12:12 & $101 \pm 27(14)$ & $101 \pm 30(17)$ \\
\hline L:D 14:10 & $94 \pm 26(14)$ & $105 \pm 27(6)$ \\
\hline \multicolumn{3}{|c|}{ Male head length (mm) mean \pm SE (n) } \\
\hline L:D 10:14 & $0.213 \pm 0.13(13)$ & $0.208 \pm 0.21(24)$ \\
\hline L:D 12:12 & $0.206 \pm 0.022(17)$ & $0.205 \pm 0.019(18)$ \\
\hline L:D 14:10 & $0.204 \pm 0.020(19)$ & $0.209 \pm 0.022(32)$ \\
\hline \multicolumn{3}{|c|}{ Male thorax length $(\mathrm{mm})$ mean $\pm \mathrm{SE}(\mathrm{n})$} \\
\hline L:D 10:14 & $0.478 \pm 0.038(13)$ & $0.464 \pm 0.041(24)$ \\
\hline L:D 12:12 & $0.477 \pm 0.046(17)$ & $0.469 \pm 0.046(18)$ \\
\hline L:D 14:10 & $0.468 \pm 0.061(19)$ & $0.482 \pm 0.038(32)$ \\
\hline
\end{tabular}

\section{DISCUSSION}

Early and late emergers do not appear to represent different adaptive peaks in Pontomyia oceana. None of the differences in morphology and fertility traits we examined was associated with early or late emergence (Tables 3 \& 4), although many of these traits (e.g. fecundity, male head and thorax lengths) were easily changed under different food regimes in both early and late emergers (Table 3). Late emergence, therefore, does not result in either higher fecundity in females or male morphological characteristics. No trade-off like those found in other organisms (see, e.g. Riessen 1999) was apparent between timing of reproduction and fitness. Alternative mating modes, frequently reported in animals (e.g. Conlan 1989), were also not substantiated, because early- and lateemerging males did not differ in characteristics (Tables $3 \& 4$ ). The two adap- 


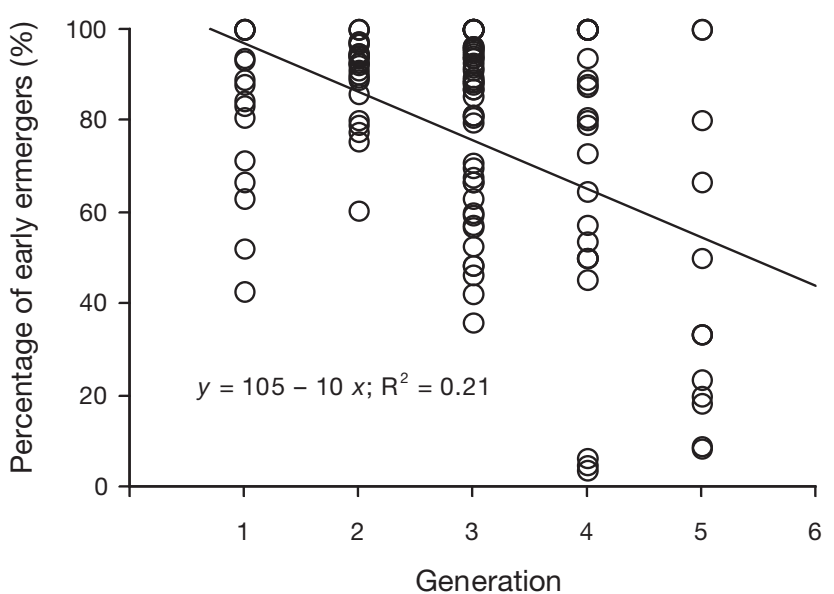

Fig. 4. Pontomyia oceana. Percentages of early emergers among offspring of individuals in different generations raised in the laboratory. Parents of generations after the first were chosen from among the early emergers of the previous generations. Generations differed significantly in percentage of early emergers among the offspring of individual females $(\mathrm{p}<$ 0.01, Kruskal-Wallis test); the second generation had the highest, and the fifth generation the lowest

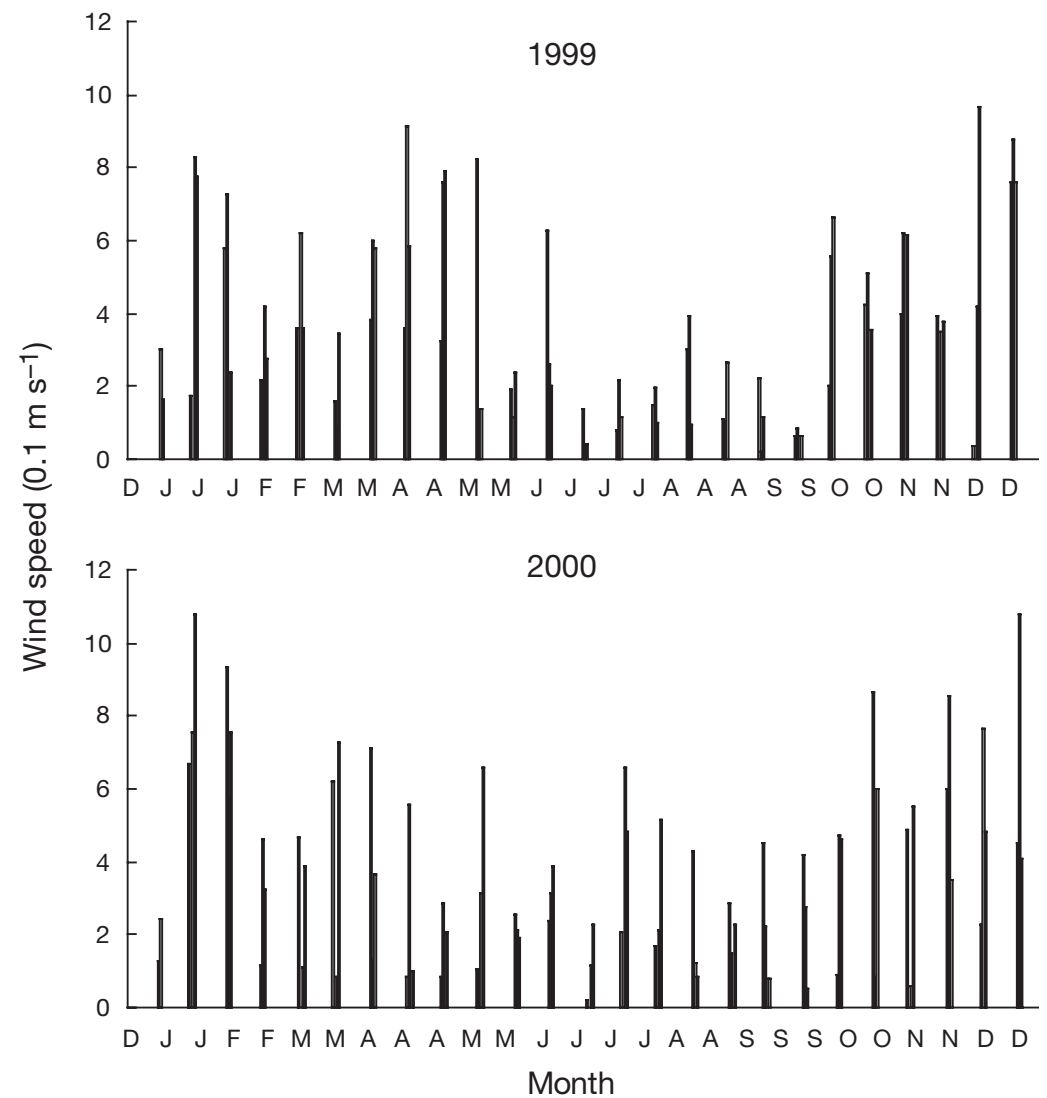

Fig. 5. Daily average wind speeds during $3 \mathrm{~d}$ periods bracketing new moons and full moons in 1999 and 2000 (data from Central Weather Bureau, Taiwan). Correlation coefficients for wind speeds between consecutive days were significantly higher than those between days $15 \mathrm{~d}$ apart tive peaks hypothesis is, therefore, not supported, at least not by the traits that we compared.

Early and late emergers are unlikely to differ in characteristics that we did not measure. A difference of $50 \%$ in generation time between the early and late emergers is probably too large to be compensated for by other traits. For example, if all other conditions were equal and population size stable, a late emerger would have to produce $n^{3 / 2}$ eggs, where $n$ is the fecundity of early emergers, to make up for the loss of time and have the same fitness as an early emerger. For a midge with an average fecundity of about 130 eggs (Table 2), late emergers would have to produce 1482 eggs, more than 11 times the number produced by early emergers. In other words, late emergers would have to be better adapted enough to gain an 11-fold reproductive advantage to compensate for their late emergence. Such differences should be easy to find if they exist.

A possibility not explored here is that early and late emergers differ in their dispersal abilities. Dimorphism in some insect species has been attributed to adaptations for dispersal distance (Venable et al. 1995, Hopper 1999, Imbert \& Ronce 2001, Mathias et al. 2001), but we deem this possibility unlikely, because early and late emergers differed in duration of benthic stage of their life cycle, most of which they spend hidden in tubes built of debris. The adult stage is the mobile stage, during which both early and late emergers, but of different cohorts, occurred on the same evenings. Extending the benthic larval stage is unlikely to give late emergers dispersal potential different from that of early emergers.

Despite the great difference in potential fitness between early- and late-emerging offspring, most individual midges produced both (see, e.g. Fig. 3). The bet-hedging hypothesis would be even more strongly supported if all individuals produced both early and late emergers, as discussed below. According to the bet-hedging hypothesis, the midges distribute their offspring into 2 emergence peaks to avoid the risk of losing all of them in 1 bout of environmental adversity. The late emergers serve as insurance that, even if all early emergers fail, some offspring remain to carry on the family.

Late emergence is, therefore, not necessarily advantageous in itself. Instead, allocating some offspring to late emergence is of benefit because all offspring of a mother are less likely to be killed in a single incident. The risk is spread to 2 emergence peaks for a mother. Despite the 
lower arithmetic average fitness in 1 generation, this trait enjoys long-term benefits because it leads to lower variation in fitness among generations. Geometric mean fitness over many generations may, therefore, actually be higher in midges producing both early and late emergers than in those that do not.

Why then, do all midges not produce both early and late emergers in our experiments? We suggest this may be an adaptation too. Pontomyia oceana is short-lived; offspring of an individual born on Day 0 are distributed in 2 peaks around 30 and 45 d later. In the next generation, they are distributed in 3 peaks, after about 60 , 75 , and $90 \mathrm{~d}$, in the next in 4 peaks, and so on. All these peaks, other than those of straight early- or straight late-emergence, are contributed to by 2 lines of descent (Fig. 6). The 'insurance' is excessive and is likely to impose a burden over many generations, when the benefits of the bet-hedging strategy can be realized. Clearly, as long as its offspring are distributed in many different peaks, a midge does not benefit by producing late emergers in every generation because the cost of producing them is high.

By producing a generation without late emergers every few generations, a lineage can distribute its offspring among as many emergence peaks and at the same time enjoy higher fitness than if they were so distributed in every generation. This intermittent bethedging produces all the insurance benefits of con-

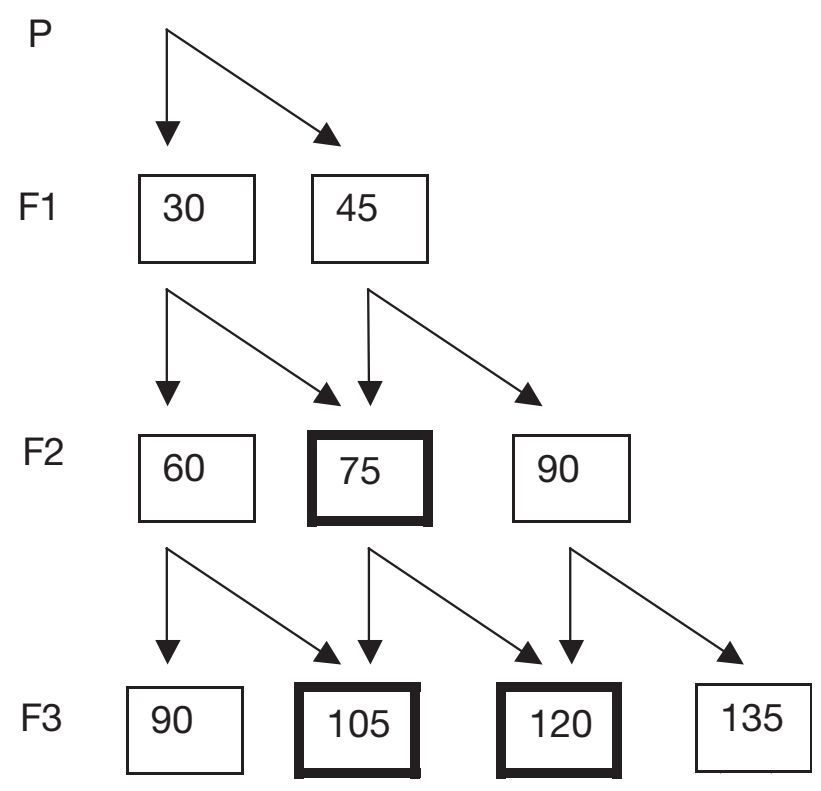

Fig. 6. Distribution of offspring in future generations of a marine midge. Squares indicate semilunar peaks of midge emergence; the numbers are no. of days following emergence of the original individual in the P generation. Vertical arrows indicate early emergers; diagonal arrows indicate late emergers. Squares 75, 105 and 120, heavily outlined in black, are contributed to by 2 lines of descent sistent bet hedging but at the same time recovers some of the cost of delayed reproduction. A further adaptation would be hedging bets under certain environments. In other words, the midges would have to associate certain environmental factors with producing only 1 , presumably the early, emergence peak. We have no evidence for this so far.

Factors that cause such unpredictable and high mortality of the intertidal midge remain to be identified. Such factors must cause high mortality or infertility of the marine midges when they are on the water surface as adults because any factor harming the larvae under water must influence both early and late emergers. We propose that the highly variable wind speed is the prime selective agent. The speed of a male marine midge on the water surface is estimated to be $>15 \mathrm{~cm}$ $\mathrm{s}^{-1}$ (Pontomyia cottoni, Cheng \& Collins 1980). Males cannot maintain locomotor control and reach immobile females if the wind speed greatly exceeds their skating speed. As mentioned above, the midges' egg strings must be laid above water on hard substrates but remain submerged when the tide rises (Soong et al. 1999), so emergence takes place on evenings with full moons or new moons, which mark the spring tides. Only a few days in each spring-tide cycle are suitable and, because wind speeds on consecutive days are significantly correlated, distributing emerging offspring within a few days of a spring tide is not effective in spreading the risk of losing all. Spreading them among 2 or more spring tides, on the other hand, may significantly lower the risk because wind speeds $15 \mathrm{~d}$ apart are much less strongly correlated.

Although Pontomyia oceana breeds only once in its lifetime, its strategy of allocating offspring into 2 emergence peaks confers some of the benefits of iteroparity, which in most situations is an evolutionarily stable strategy in a variable environment (see Benton \& Grant 1999).

Acknowledgements. We thank M. Adreani, P. S. Cranston, N. D. Fogarty, D. Houle, D. R. Levitan, P. Munguia, A. B. Thistle, H. Y. Yan and 2 anonymous reviewers for commenting on an early version of the manuscript. This research was partly sponsored by a grant (NSC92-2311-B-110-001) from the National Science Council of Taiwan, ROC.

\section{LITERATURE CITED}

Benton TG, Grant A (1999) Optimal reproductive effort in stochastic, density-dependent environments. Evolution 53:677-688

Blake JA, Kudenov JD (1981) Larval development, larval nutrition and growth for two Boccardia species (Polychaeta: Spionidae) from Victoria, Australia. Mar Ecol Prog Ser 6:175-182

Bologna PAX (1998) Growth, production, and reproduction in bay scallops Argopecten irradians concentricus (Say) from the northern Gulf-of-Mexico. J Shellfish Res 17:911-917 
Bradford MJ, Roff DA (1997) An empirical-model of diapause strategies of the cricket Allonemobius socius. Ecology 78: $442-451$

Cao JR (1997) The study of synchronized eclosion of the marine midge Pontomyia oceana (Diptera: Chironomidae). Masters thesis, Institute of Marine Biology, Kaohsiung

Chen GF (1993) A preliminary study of life history of two marine midges Pontomyia spp. (Diptera: Chironomidae). MS thesis, Institute of Marine Biology, Kaohsiung

Cheng L, Collins JD (1980) Observations on behavior, emergence and reproduction of the marine midges Pontomyia (Diptera: Chironomidae). Mar Biol 58:1-5

Collier RH, Finch S, Anderson M (1989) Laboratory studies on late-emergence in the cabbage root fly (Delia radicum). Entomol Exp Appl 50:233-240

Conlan KE (1989) Delayed reproduction and adult dimorphism in males of the amphipod genus Jassa (Corophioidea: Ischyroceridae): an explanation for systematic confusion. J Crustac Biol 9:601-625

Danforth BN (1999) Emergence dynamics and bet hedging in a desert bee, Perdita portalis. Proc R Soc Lond Ser B 266:1985-1994

Forcada J, Hammond PS, Aguilar A (1999) Status of the Mediterranean monk seal Monachus monachus in the Western Sahara and the implications of a mass mortality event. Mar Ecol Prog Ser 188:249-261

Foster WA, Moreton RB (1981) Synchronization of activity rhythms with the tide in a saltmarsh collembolan: Anurida maritima. Oecologia 50:265-270

Gross MR (1991) Salmon breeding behavior and life history evolution in changing environments. Ecology 72:1180-1186

Hopper KR (1999) Risk-spreading and bet-hedging in insect population biology. Annu Rev Entomol 44:535-560

Imbert E, Ronce O (2001) Phenotypic plasticity for dispersal ability in the seed heteromorphic Crepis sancta (Asteraceae). Oikos 93:126-134

Krug PJ, Zimmer RK (2000) Developmental dimorphism and expression of chemosensory-mediated behavior: habitat selection by a specialist marine herbivore. J Exp Biol 203: 1741-1754

Kubler JE, Davison IR (1993) High-temperature tolerance of photosynthesis in the red alga Chondrus crispus. Mar Biol 117:327-335

Lee PH (1999) The effect of temperature on synchronized eclosion and the study of eclosion rhythm of the marine midge Pontomyia oceana. Masters thesis, Institute of Marine Biology, Kaohsiung

Lessios HA (1992) Testing electrophoretic data for agreement with Hardy-Weinberg expectations. Mar Biol 112:517-523

Levin LA (1984) Multiple patterns of development in Streblospio benedicti Webster (Spionidae) from three coasts of North America. Biol Bull (Woods Hole) 166:494-508

Lewis JR (1964) The ecology of rocky shores. English Universities Press, London

Lu CL, Chen SH (1998) Multiple linear interdependent models (Mlim) applied to typhoon data from China. Theor Appl Climatol 61:143-149

Mathias A, Kisdi E, Oliveri I (2001) Divergent evolution of dispersal in a heterogeneous landscape. Evolution 55:246-259

McLachlan AJ (1989) Animal populations at extreme densities: size dimorphism by frequency dependent selection in ephemeral habitats. Funct Ecol 3:633-643

McLachlan A, Ladle R (2001) Life in the puddle: behavioural and life-cycle adaptations in the Diptera of tropical rain pools. Biol Rev 76:377-388

Morgan SG, Christy JH (1994) Plasticity, constraint, and optimality in reproductive timing. Ecology 75:2185-2203
Nadeau TL, Howard-Williams C, Castenholz RW (1999) Effects of solar UV and visible irradiance on photosynthesis and vertical migration of Oscillatoria sp. (Cyanobacteria) in an Antarctic microbial mat. Aquat Microb Ecol 20: 231-243

Narita K (1998) Effects of seed release timing on plant lifehistory and seed production in a population of a desert annual, Blepharis sindica (Acanthaceae). Plant Ecol 136: 195-203

Neumann D (1976) Adaptations of chironomids to intertidal environments. Annu Rev Entomol 21:387-414

Neumann D (1986) Diel eclosion rhythm of a sublittoral population of the marine insect Pontomyia pacifica. Mar Biol 90:461-465

Neumann D, Heimbach F (1985) Circadian range of entrainment in the semilunar eclosion rhythm of the marine insect Clunio marinus. J Insect Physiol 31:549-557

Omori K (1995) The adaptive significance of a lunar or semilunar reproductive cycle in marine animals. Ecol Model 82:41-49

Pake CE, Venable DL (1996) Seed banks in desert annuals implications for persistence and coexistence in variable environments. Ecology 77:1427-1435

Palmer JD (1996) Time, tide and the living clocks of marine organisms. Am Sci 84:571-578

Philippi T (1993) Bet-hedging germination of desert annuals: beyond the first year. Am Nat 142:474-487

Philippi T, Seger J (1989) Hedging one's evolutionary bets, revisited. Trends Ecol Evol 4:41-44

Qian PY, Chia FS (1992) Effects of diet type on the demographics of Capitella sp. (Annelida: Polychaeta): lecithotrophic development vs. planktotrophic development. J Exp Mar Biol Ecol 157:159-179

Riessen H (1999) Chaoborus predation and delayed reproduction in Daphnia: a demographic modeling approach. Evol Ecol 13:339-363

Ruyck AMCD, Mclachlan A, Donn TE (1991) The activity of three intertidal sand beach isopods (Flabellifrea: Cirolanidae). J Exp Mar Biol 146:163-180

Saigusa M, Akiyama T (1995) The tidal rhythm of emergence, and the seasonal variation of this synchrony, in an intertidal midge. Biol Bull 188:166-178

Schmidt PS, Rand DM (1999) Intertidal microhabitat and selection at MPI: interlocus contrasts in the northern acorn barnacle, Semibalanus balanoides. Evolution 53:135-146

Simovich MA, Hathaway SA (1997) Diversified bet-hedging as a reproductive strategy of some ephemeral pool anostracans (Branchiopoda). J Crustac Biol 17:38-44

Solbreck C (1991) Unusual weather and insect population dynamics: Lygaeus eqestris during an extinction and recovery period. Oikos 60:343-350

Soong K, Chen GF, Cao JR (1999) Life history studies of the flightless marine midges Pontomyia spp. (Diptera: Chironomidae). Zool Stud 38:466-473

Sunobe T, Ohta T, Nakazono A (1995) Mating system and spawning cycle in the blenny, Istiblennius enosimae, at Kagoshima, Japan. Environ Biol Fishes 43:195-199

Venable DL, Dyreson E, Morales E (1995) Population dynamic consequences and evolution of seed traits of Heterosperma pinnatum (Asteraceae). Am J Bot 82:410-420

Waldbauer GP (1978) Phenological adaptation and the polymodal emergence patterns of insects. In: Dingle $\mathrm{H}$ (ed) Evolution of insect migration and diapause. SpringerVerlag, New York, p 127-144

Zebe E, Schiedek D (1996) The lugworm Arenicola marina: a model of physiological adaptation to life in intertidal sediments. Helgol Meeresunters 50:37-68

Submitted: April 2, 2004; Accepted: September 7, 2004

Proofs received from author(s): January 19, 2005 